\title{
Sosialisasi Penggunaan Sistem Informasi Sertifikat Elektronik pada Lembaga Penjamanin Mutu Pendidikan Provinsi Bali
}

\author{
I Komang Arya Ganda Wiguna ${ }^{1}$, Ida Bagus Gede Sarasvananda ${ }^{2}$ \\ STMIK STIKOM Indonesia, J1. Tukad Pakerisan No.97, Panjer, Kec. Denpasar Sel., Kota \\ Denpasar, Bali $80225^{1,2}$ \\ Email: kmaryagw@stiki-indonesia.ac.id ${ }^{1}$
}

\begin{abstract}
ABSTRAK
Lembaga Penjamin Mutu Pendidikan Provinsi Bali atau disingkat LPMP adalah unit pelaksana teknis kementerian Pendidikan dan kebudayaan. LPMP mempunyai fungsi sebagai pengendali penyelenggaraan Pendidikan oleh satuan Pendidikan untuk mewujudkan Pendidikan yang bermutu. Tugas LPMP adalah melakukan penjaminan mutu Pendidikan dasar dan menengah berdasarkan kebijakan Menteri Pendidikan dan Kebudayaan. Guna mewujudkan visi dan misi dari LPMP Bali, salah satu kegiatan yang secara berkala diadakan adalah kegiatan seminar/workshop kepada para guru. Kegiatan seminar/workshop kepada para guru ini bertujuan untuk meningkatan mutu Pendidikan dasar dan Pendidikan menengah dalam pencapaian standar nasional. Sebagai bentuk bukti partisipasi bagi para guru maka setiap guru yang mengikuti kegiatan seminar/workshop akan mendapatkan sertifikat. Proses pengelolaan dan penerbitan sertifikat kegiatan di lingkungan LPMP Provinsi Bali saat ini masih dilakukan secara sederhana menggunakan aplikasi Microsoft office sehingga diperlukan suatu sistem yang dapat mengelola data sertifikat. e-Sertifikat LPMP Bali merupakan sistem manajemen sertifikat elektronik yang diperuntukkan di lingkungan LPMP Provinsi Bali guna memudahkan penyelenggara kegiatan di LPMP Provinsi Bali dalam memanajemen sertifikat yang akan diberikan kepada peserta dan narasumber dan pengarsipan dapat berjalan dengan baik. Kegiatan pengabdian kepada masyarakat ini bertujuan untuk memberikan sosialisasi cara penggunaan e-Sertifikat kepada seluruh pengguna sistem di lingkungan LPMP Provinsi Bali. Hasil dari kegiatan ini, mitra dapat melakukan pengelolaan, input peserta, penerbitan dan distirbusi sertifikat menggunakan sistem e-Sertifikat.
\end{abstract}

Kata kunci: LPMP Provinsi Bali; E-Sertifikat; Sistem Informasi; Sosialisasi Penggunaan Sistem

\section{ABSTRACT}

LPMP is the technical implementation unit of the Ministry of Education and culture. LPMP has the function of controlling the implementation of education by the education unit to create quality education. The task of LPMP is to guarantee the quality of primary and secondary education based on the policies of the Minister of Education and Culture. To realize the vision and mission of LPMP Bali, one of the regularly held activities is seminar/workshop activities for teachers. This activity aims to improve the quality of primary and secondary education in achieving national standards. As proof of teacher participation, every teacher who participates in the seminar/workshop will get a certificate. Managing and issuing activity certificates in the LPMP Bali is still used only using the Microsoft office application. A system that can manage certificate data is needed. The e-Certificate of LPMP Bali is an electronic certificate management system intended for the LPMP Bali to make it easier for activity organizers in the LPMP Bali to manage certificates given to participants and resource persons, and archiving can run well. This community service activity aims to provide socialization on eCertificates to all system users in the LPMP Bali. As a result of this activity, partners can manage, input participants, issue, and distribute certificates using the e-Certificate system.

Keywords: LPMP Bali; E-Certificate; Information System; System Training 


\section{PENDAHULUAN}

Menurut Peraturan Menteri Pendidikan Dan Kebudayaan Republik Indonesia No 26 Tahun 2020 tentang Organisasi Dan Tata Kerja Unit Pelaksana Teknis Kementerian Pendidikan Dan Kebudayaan, Lembaga Penjamin Mutu Pendidikan Provinsi Bali atau disingkat LPMP adalah unit pelaksana teknis Kementerian Pendidikan dan Kebudayaan. LPMP mempunyai fungsi sebagai pengendali penyelenggaraan Pendidikan oleh satuan Pendidikan untuk mewujudkan Pendidikan yang bermutu (Mendikbud, 2020). LPMP tersebar diseluruh provinsi yang ada di Indonesia. LPMP Provinsi Bali adalah lembaga yang berada di bawah Direktorat Jenderal Pendidikan Dasar dan Menengah Kementerian Pendidikan dan Kebudayaan.

Guna mewujudkan visi dan misi dari LPMP Bali, salah satu kegiatan yang secara berkala diadakan adalah kegiatan seminar/workshop kepada para guru. Kegiatan seminar/workshop kepada para guru ini bertujuan untuk meningkatan mutu Pendidikan dasar dan Pendidikan menengah dalam pencapaian standar nasional. Sebagai bentuk bukti partisipasi bagi para guru maka setiap guru yang mengikuti kegiatan seminar/workshop akan mendapatkan sertifikat.

Proses pengelolaan dan penerbitan sertifikat kegiatan di lingkungan LPMP Provinsi Bali saat ini masih dilakukan secara konvensional dengan bantuan aplikasi Microsoft Office untuk mendata peserta kegiatan seminar/workshop dan Corel Draw untuk mendesain sertifikat. Dikarenakan masih dilakukan secara konvensional, maka terdapat beberapa kekurangan diantaranya yaitu: proses pencantuman nama peserta/narasumber pada sertifikat diinput satu persatu sehingga memerlukan waktu dan proses yang lebih lama, proses validasi sertifikat yang diterbitkan masih dilakukan secara manual yaitu Pegawai akan membawa sertifikat yang telah dicetak untuk diserahkan kepada Kepala LPMP, kemudian Kepala LPMP akan memvalidasi dengan menandatangani sertifikat tersebut, proses pendistribusian sertifikat masih dilakukan secara manual yaitu dengan memberikan secara langsung sertifikat kepada yang bersangkutan, sulitnya melakukan rekapitulasi terhadap sertifikat yang telah diterbitkan, dan tidak dapat melakukan arsip data sertifikat dikarenakan tata cara penyimpanan data hanya pada lokal komputer, sehingga jika terjadi kerusakan terhadap komputer tersebut bias mengakibatkan kehilangan data. Proses pembuatan laporan setiap bulannya sulit dilakukan jika masih dilakukan secara manual (Triono dkk, 2019).

Berdasarkan permasalahan mitra, maka dibutuhkan suatu sistem yang dapat mengelola sertifikat yang diterbitkan oleh LPMP Provinsi Bali. Sistem yang telah dibangun yaitu, 
"Sistem Informasi Manajemen Sertifikat Elektronik LPMP Provinsi Bali” dengan alias eSertifikat. e-Sertifikat LPMP Bali merupakan sistem manajemen sertifikat elektronik yang diperuntukan di lingkungan LPMP Provinsi Bali guna memudahkan penyelenggara kegiatan di LPMP Provinsi Bali dalam memanajemen sertifikat yang akan diberikan kepada peserta dan narasumber. Dengan adanya e-Sertifikat juga memberikan kemudahan bagi staff untuk melakukan proses cetak sertifikat (Prabowo dan Syani, 2017). Sertifikat elektoronik atau eSertifikat lebih tahan lama dan berguna daripada sertifikat dalam bentuk hardcopy. Keuntungan lain e-Sertifikat berbasis web dapat diakses pengguna darimana saja (Suteja dkk, 2019; Gokulakrishnan dan Sarma, 2020; Wilson dan Argles, 2010).

Kegiatan pengabdian kepada masyarakat ini hanya berfokus kepada kegiatan sosialisasi cara penggunaan dari sistem e-Sertifikat. Kegiatan sosialisasi bertujuan untuk memberikan pelatihan cara penggunaan e-Sertifikat kepada seluruh stakeholder yang terlibat dalam penggunaan sistem.

\section{METODE}

Pelaksanaan kegiatan pengabdian kepada masyarakat diadakan selama dua hari. Dimulai dari tanggal 13 Agustus hingga 14 Agustus 2020 dari pukul 09.00 hingga 14.00 WITA. Kegiatan Pengabdian kepada Masyarakat ini diikuti oleh Ketua LPMP Provinsi Bali, Kasubbag Umum, Kepala Seksi Sistem Informasi dan beberapa perwakilan dari masingmasing Seksi dan Sub bagian LPMP Provinsi Bali sebanyak 18 orang. Dikarenakan kegiatan ini dilaksanakan ditengah pandemi yang masih berlangsung maka kegiatan ini dilaksanakan dengan mengikuti standar protokol kesehatan yang telah ditetapkan oleh Menteri Kesehatan dan jumlah peserta tidak lebih dari 25 orang. Sebelum pelaksanaan kegiatan dimulai, peserta dan narasumber terlebih dahulu dilakukan pengecekan suhu tubuh guna memastikan bahwa peserta dan narasumber memiliki suhu tubuh dibawah 37,3. Adapun lokasi dilaksanakannya sosialisasi cara penggunaan sistem informasi sertifikat elektornik yaitu di Ruang Teleconference LPMP Provinsi Bali. Peta lokasi dapat dilhat pada gambar 1. 


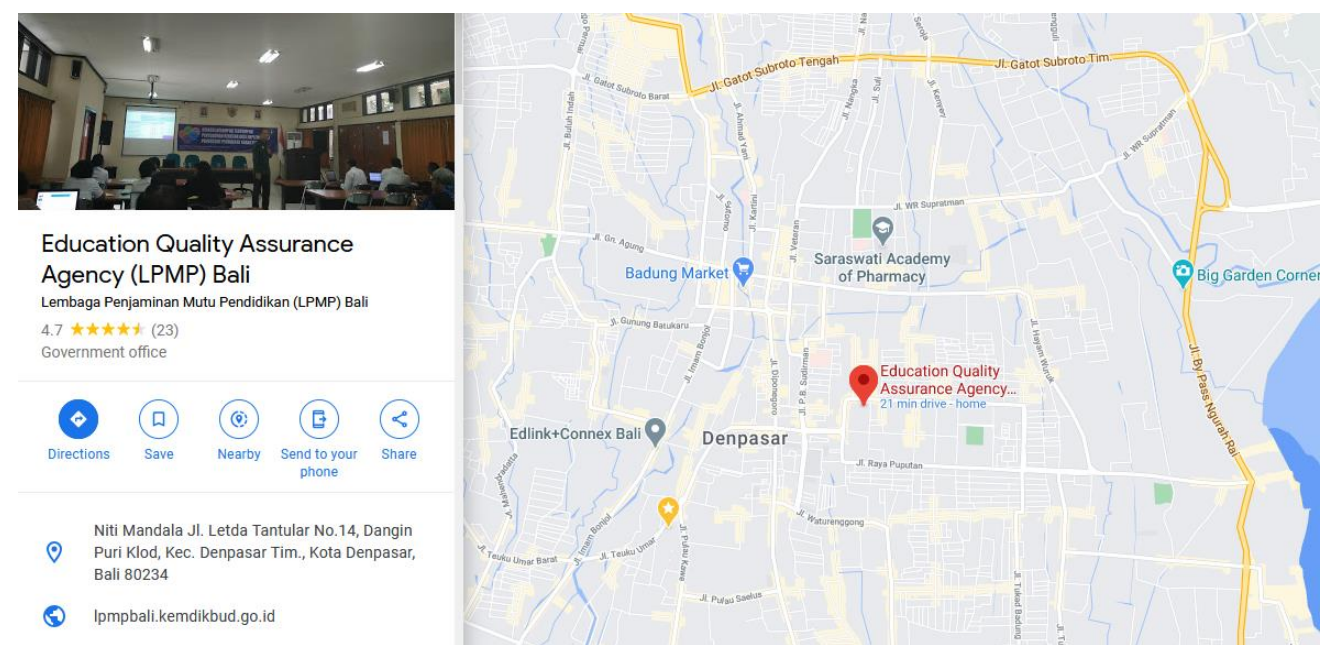

Gambar 1. Tempat Sosialisasi Cara Penggunaan Sistem

Metode yang digunakan dalam pelaksanaan kegiatan ini digambarkan pada Gambar 2.
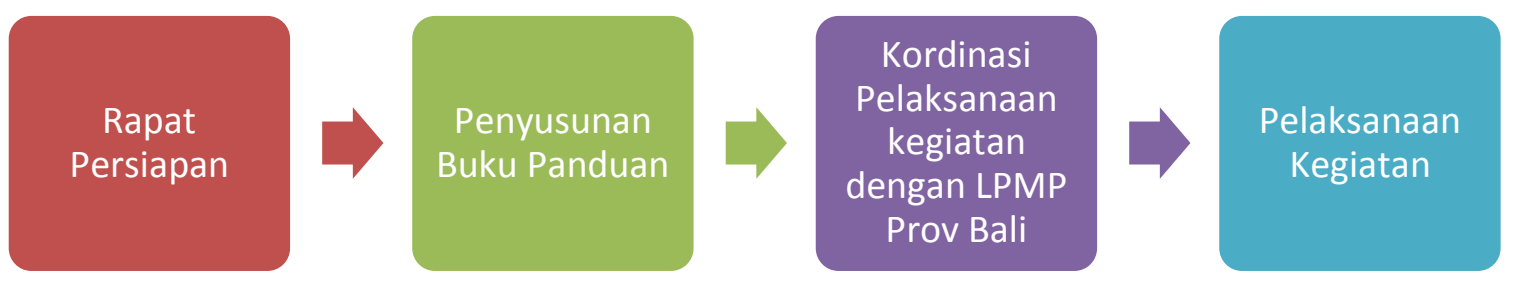

Gambar 2. Metode Penelitian

\section{Rapat Persiapan}

Rapat persiapan dilakukan sebelum pelaksanaan kegiatan, adapun agenda yang dibahas dalam rapat persiapan yaitu: penyusunan buku panduan, penyusunan jadwal kegiatan, dan teknis pelaksanaan kegiatan sosialisasi.

\section{Penyusunan Buku Panduan}

Penyusunan materi dan buku panduan bertujuan untuk memberikan penjelasan secara detail dari sistem informasi manajemen sertifikat, sehingga jika dikemudian hari pengguna sistem memiliki kendala dalam cara penggunaan sistem, dapat melihat buku panduan terlebih dahulu.

\section{Kordinasi Pelaksanaan Kegiatan dengan LPMP Provinsi Bali}

Kordinasi dengan pihak LPMP Provinsi Bali dilakukan dengan cara menghubungi menggunakan saluran telepon seluler. Kordinasi dilakukan dengan tujuan untuk menentukan tanggal kegiatan serta teknis pelaksanaan kegiatan yang mengikuti standar protokol kesehatan dari Menteri Kesehatan karena kegiatan dilaksanakan ditengah pandemic yang masih berlangsung. 


\section{Pelaksanaan Kegiatan}

Adapun tahapan pelaksanaan kegiatan pengabdian kepada masyarakat ini adalah sebagai berikut:

Hari Pertama (i) Pembukaan kegiatan PKM oleh Kepala LPMP Provinsi Bali (ii) Pemaparan Materi Pengenalan Sistem Informasi Manajemen Sertifikat Elektronik (iii) Sesi Tanya Jawab. Hari Kedua (i) Sosialisasi penggunaan Sistem Informasi Manajemen Sertifikat Elektronik (ii) Pendampingan praktek dan konsultasi secara langsung antara peserta ddengan narasumber terkait penggunaan sistem. (iii) Tanya Jawab (iv) Penutupan.

\section{HASIL, PEMBAHASAN, DAN DAMPAK}

Sosialisai penggunaan sistem dilaksanakan di Ruangan Teleconference LPMP Provinsi Bali dengan diikuti oleh seluruh stakeholder yang terlibat meliputi: Kepala LPMP Provinsi Bali, Kasubbag Umum, Kepala Seksi Sistem Informasi dan beberapa perwakilan dari masing-masing Seksi dan Sub bagian LPMP Provinsi Bali. Pelaksanaan kegiatan sosialisasi dilaksanakan selama dua hari yang dimulai dari tanggal 13 - 14 Agustus 2020 dari pukul dari pukul 09.00 hingga 14.00 WITA. Pelaksanaan kegiatan dilaksanakan selama dua hari dengan harapan bahwa pengguna sistem dapat memahami secara jelas bagaimana cara penggunaan dari sistem informasi sertifikat elektornik. Pun sudah dibuatkan buku panduan dari penggunaan sistem, namun kegiatan sosialisasi masih sangat dibutuhkan untuk melakukan praktek penggunaan sistem secara langsung.

Kegiatan hari pertama dibuka secara langsung oleh Kepala LPMP Provinsi Bali, Kepala LPMP Provinsi Bali berharap dengan adanya sistem e-Sertifikat, dapat mempermudah dalam pengelolaan, penerbitan serta pendistribusian sertifikat yang dilakukan secara online, sehingga sertifikat yang diterbitkan tidak lagi menggunakan kertas. Acara dilanjutkan dengan pemaparan materi oleh Narasumber dengan topik pengenalan fungsi dan manfaat dari sistem e-Sertifikat. Terakhir, kegiatan hari pertama ditutup dengan sesi tanya jawab. Gambar 3 merupakan kegiatan pengabdian masyarakat hari pertama. Kegiatan hari kedua dilanjutkan dengan sosialisasi dan praktek cara penggunaan sistem eSertifikat. Seluruh peserta yang hadir akan memperankan tugas sesuai dengan role sistem. Adapun role yang telah ditentukan yaitu: Admin, Penanggung Jawab Kegiatan, Kepala LPMP dan Peserta (penerima sertifikat). Admin memiliki tugas dan tanggung jawab penuh terhadap pengelolaan sistem, Penanggung Jawab Kegiatan memiliki tugas untuk mengelola kegiatan yang dimulai dari pendaftaran kegiatan, input peserta/narasumber dan distribusi sertifikat, Kepala LPMP memiliki tugas untuk memvalidasi kegiatan yang didaftarkan oleh 
Penanggung Jawab Kegiatan, dan Peserta dapat melakukan pencarian serta dapat mengecek validasi terhadap sertifikat yang diterima. Gambar 4 merupakan pelaksanaan kegiatan pengabdian kepada masyarakat hari kedua.

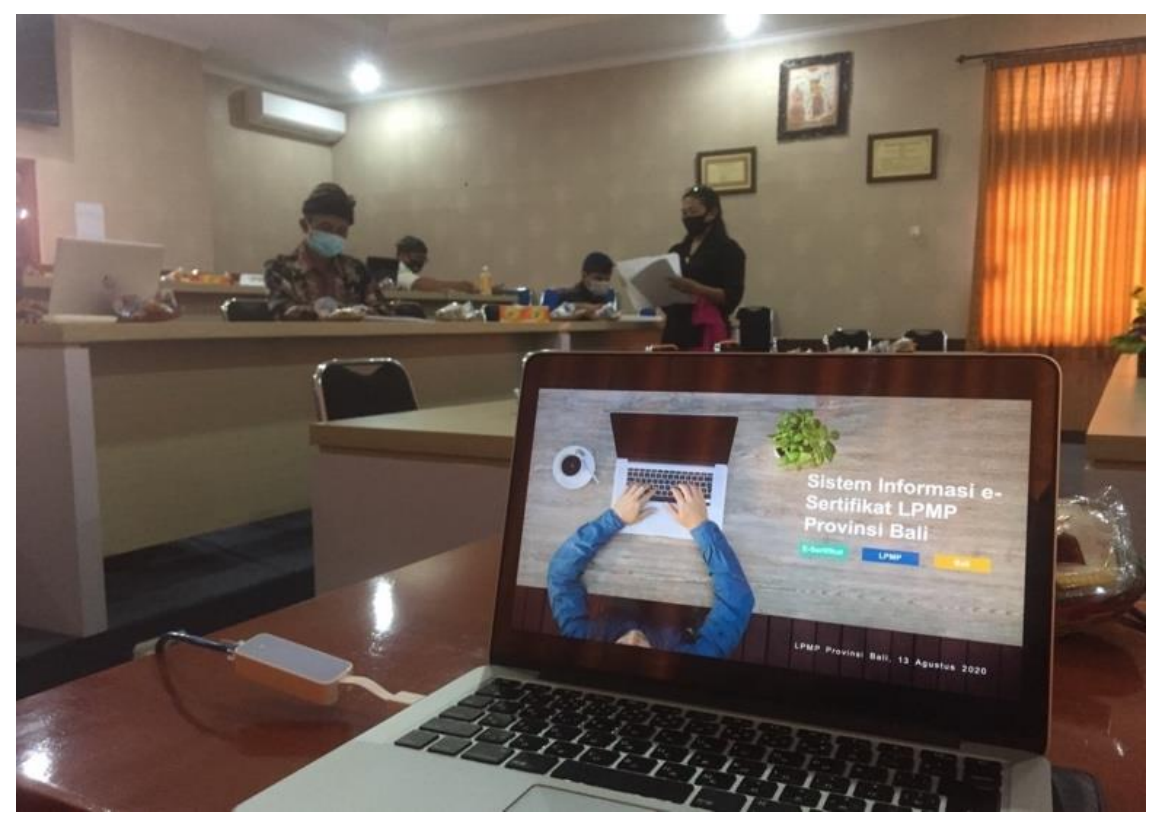

Gambar 3 Kegiatan pengabdian kepada masyarakat hari pertama.

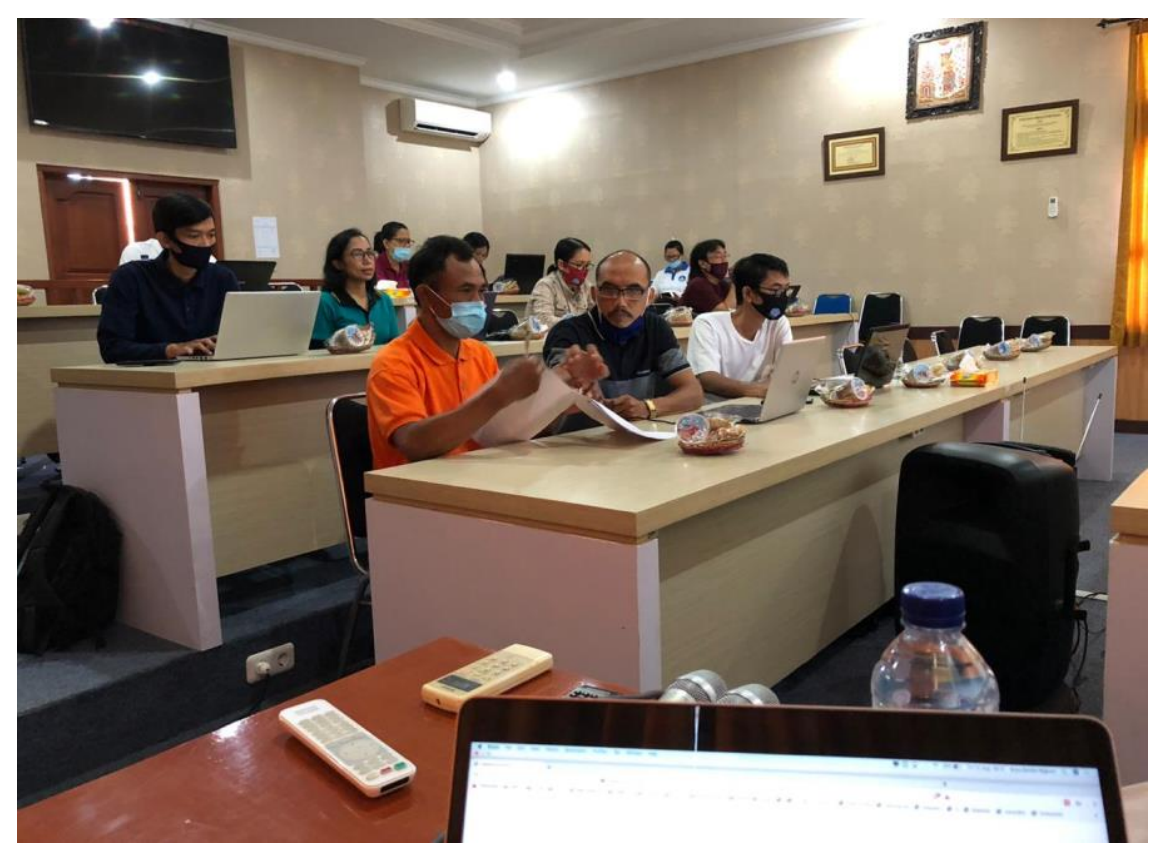

Gambar 4. Pelaksanaan kegiatan pengadian kepada masyarakat hari kedua 


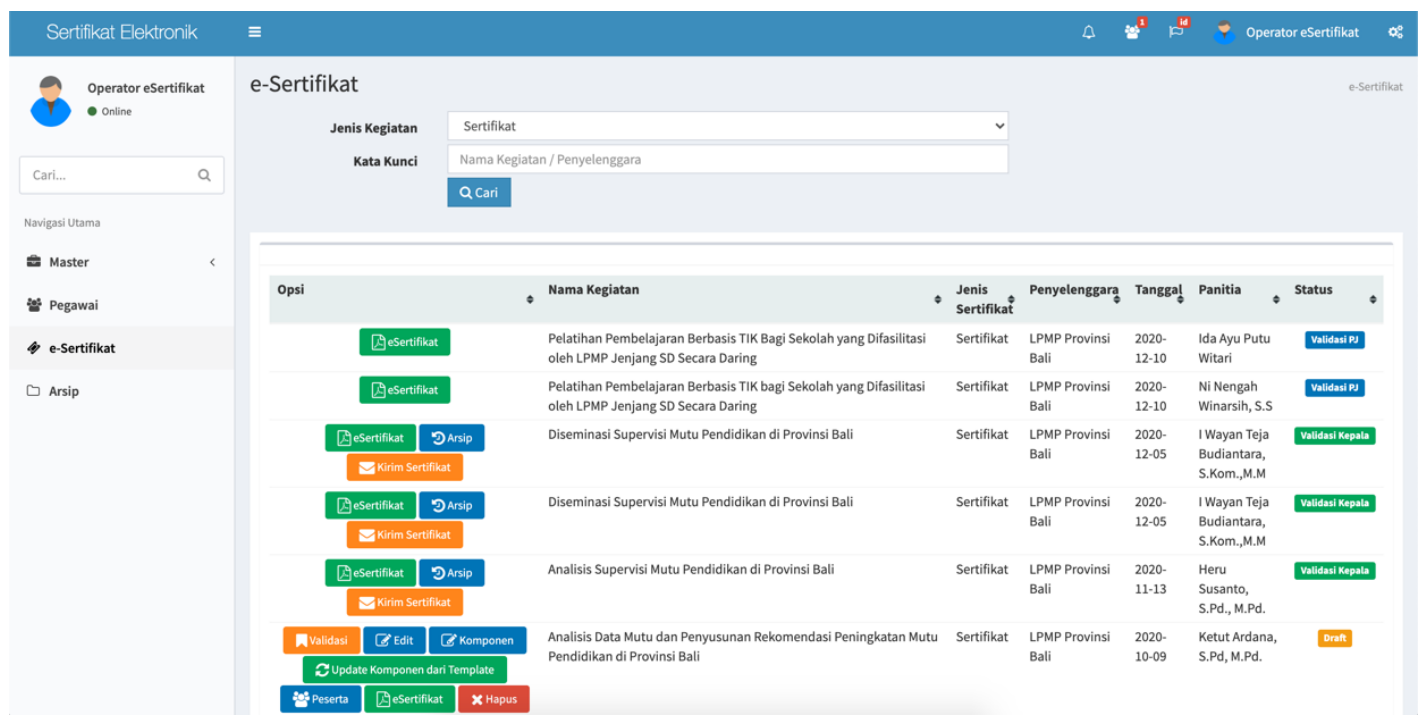

Gambar 5 Tampilan daftar sertifikat elektronik LPMP Provinsi Bali

Dampak dilaksanakannya kegiatan sosialisasi ini, secara tidak langsung sistem akan diuji coba baik dari segi alur maupun fungsi dari sistem itu sendiri dan juga untuk memastikan sistem dapat berjalan sesuai dengan yang diharapkan. Kegiatan sosialisasi cara penggunaan sistem telah berhasil dilakukan, hal tersebut terlihat dari pengguna telah berhasil melakukan pengelolaan, input peserta, penerbitan dan distribusi sertifikat tadi, dapat dilihat pada Gambar 5.

\section{SIMPULAN}

Pelaksanaan kegiatan pengabdian kepada masyarakat dengan judul Sosialisasi Penggunaan Sistem Informasi Sertifikat Elektronik di LPMP Provinsi Bali telah berhasil dilaksanakan. Hal ini ditunjukkan dengan pengguna telah berhasil melakukan pengelolaan, input data peserta/narasumber, penerbitan dan distribusi sertifikat menggunakan sistem eSertifikat. Pimpinan dan Pegawai LPMP Provinsi Bali ikut berperan aktif memberikan masukan terhadap sistem yang disosialisakan.

\section{UCAPAN TERIMAKASIH}

Kami ucapkan terima kasih kepada LPPM STMIK STIKOM Indonesia yang telah memberikan dukungan dana dalam pelaksanaan pengabdian masyarakat Tahun 2020 .

\section{DAFTAR PUSTAKA}

Gokulakrishnan, S. and Sarma, C. S. (2020) An Approach to E-Certificate Designing with Auto-Emailing. International Journal of Scientific Research \& Engineering Trends. Volume 6, Issue 3, May-June- 2020. 
Mendikbud. (2020) Peraturan Menteri Pendidikan Dan Kebudayaan Republik Indonesia Nomor 26 Tahun 2020 Tentang Organisasi Dan Tata Kerja Unit Pelaksana Teknis Kementerian Pendidikan Dan Kebudayaan. Jakarta.

Prabowo, F.A., Syani, M. (2016). Sistem Informasi Pengolahan Sertifikat Berbasis Web di Divisi Training Seamolec. Jurnal Masyarakat Informatika Indonesia, 2(1), 73-81.

Suteja, Bernard \& Imbar, Radiant \& Johan, Meliana. (2019). Implementation of QR Code on E-Certificate for Events at Maranatha Christian University. Conference SENATIK STT Adisutjipto Yogyakarta. doi: http://dx.doi.org/10.28989/senatik.v5i0.396

Triono, Hakim, Z., Nursyi, M. (2019). Sistem Informasi Proses Pengambilan Sertifikat Pelaut pada BP2IP Tangerang. Jurnal Sisfotek Global, 9(2), 65-70.

Wilson, L. C., and Argles, D. (2010) Towards a Framework of a Secure E-Qualification Certificate System. Second International Conference on Computer Modeling and Simulation, Sanya, Hainan, 2010, pp. 493-500, doi: https://doi.org/10.1109/ICCMS.2010.195 